\title{
Mitochondria in the pathogenesis of diabetes: a proteomic view
}

\author{
Xiulan Chen ${ }^{1}$, Shasha Wei ${ }^{1,2}$, Fuquan Yang ${ }^{1 凶}$ \\ ${ }^{1}$ Key Laboratory of Protein and Peptide Pharmaceuticals and Laboratory of Proteomics, Institute of Biophysics, Chinese \\ Academy of Sciences, Beijing 100101, China \\ ${ }^{2}$ Graduate University of Chinese Academy of Sciences, Beijing 100149, China \\ $\square$ Correspondence: fqyang@sun5.ibp.ac.cn \\ Received June 7, 2012 Accepted June 13, 2012
}

\begin{abstract}
Diabetes mellitus is a complex metabolic disorder characterized by chronic hyperglycemia due to absolute or relative lack of insulin. Though great efforts have been made to investigate the pathogenesis of diabetes, the underlying mechanism behind the development of diabetes and its complications remains unexplored. Cumulative evidence has linked mitochondrial modification to the pathogenesis of diabetes and its complications and they are also observed in various tissues affected by diabetes. Proteomics is an attractive tool for the study of diabetes since it allows researchers to compare normal and diabetic samples by identifying and quantifying the differentially expressed proteins in tissues, cells or organelles. Great progress has already been made in mitochondrial proteomics to elucidate the role of mitochondria in the pathogenesis of diabetes and its complications. Further studies on the changes of mitochondrial protein specifically post-translational modifications during the diabetic state using proteomic tools, would provide more information to better understand diabetes.
\end{abstract}

KEYWORDS mitochondria proteomics, T1DM, T2DM, diabetes complication

\section{INTRODUCTION}

Diabetes mellitus has attracted the world's attention with the alarming increase in number of positive diagnoses. The International Diabetes Federation estimated that there were 366 million people with diabetes in 2011 (Whiting et al., 2011). The estimated number of diagnosed cases has risen steadily over the past decade (151, 194, 246 and 285 million cases in $2000,2003,2006$, and 2010, respectively) and is expected to rise to 552 million by 2030 (Whiting et al., 2011). Diabetes mellitus is a complex metabolic disorder characterized by abnormal glucose homeostasis due to absolute or relative lack of insulin. Based on etiology, diabetes can be divided into two main forms: type 1 diabetes mellitus (T1DM); and type 2 diabetes mellitus (T2DM). T1DM is an autoimmune disease resulting from destruction of the insulin secreting pancreatic $\beta$ cells leading to a complete absence of insulin in the body (Sparre et al., 2005), and accounts for $5 \%-10 \%$ of all diabetic cases. T2DM is characterized by relative insulin deficiency due to decreased insulin secretion by the $\beta$-cells and/or the decreased effect of insulin in the target tissues, also known as insulin resistance (IR) (Zimmet et al., 2001). T2DM is the most common form of diabetes and affects over $90 \%$ of diabetic patients. In addition to the above, metabolic changes that occur during diabetes can also result in macrovascular complications leading to heart disease or peripheral arterial disease, and also the possibility of developing nephropathy, retinopathy, and neuropathy, all of which decrease the patient's quality of life and impose further burden on the health-care system (Madsen-Bouterse and Kowluru, 2008).

Despite intensive efforts to investigate the pathogenesis of diabetes, the triggering factors and underlying mechanisms behind the development of diabetes and its complications remain elusive. Cumulative evidence indicates that diabetes and its complications, at least partially, result from pathogenic process at the mitochondrial level (Lamson and Plaza, 2002; Sivitz and Yorek, 2009).

In this review, we will address the close association between mitochondrial alterations and diabetes in different tissues, and the application of mitochondrial proteomics to elu- 
cidate the pathogenesis of diabetes and its complications.

\section{A BRIEF INTRODUCTION TO MITOCHONDRIA}

Mitochondria are eukaryotic organelles that lie at the heart of cell life and death. Mitochondria perform several fundamental cellular processes including energy production, substance metabolism, apoptosis and ion homeostasis (Duchen, 2004). Mitochondria are unique organelles with a two-layer membrane structure which separate the organelle into four compartments: the outer membrane, the intermembrane space, the inner membrane, and the matrix. The mitochondrial outer membrane, which encloses the entire organelle, contains numerous integral proteins that are involved in solute exchange, protein importing, and enzymes involved in diverse activities, including fatty acid elongation (Ruiz-Romero and Blanco, 2009). The intermembrane space, the space between the two membranes, contains proteins that play major roles in mitochondrial energetics and apoptosis, most notably cytochrome c. The mitochondrial inner membrane, which is highly impermeable to all molecules, contains proteins that perform oxidative phosphorylation (OXPHOS), protein importing and substance exchange (Distler et al., 2008). The mitochondrial matrix, the space enclosed by the inner membrane, contains about two-thirds of the total protein in the mitochondria, and is also the place where mitochondrial genome is contained.

Mitochondria have their own genome and the machinery to manufacture their own RNAs and proteins, though the mitochondrial genome (mtDNA) only encodes a fraction of proteins that are fundamental for mitochondrial function. For example, mammalian mtDNA only encodes 2 rRNAs, 22 tRNAs and 13 polypeptides that are all components of the respiration chain (Wallace, 1999), other mitochondrial proteins are encoded by the nuclear genome and imported into mitochondria. The importance of mtDNA has been demonstrated by the appearance of mtDNA mutations in a variety of diseases including diabetes (Suzuki et al., 2005; Chan, 2006).

\section{MITOCHONDRIAL FUNCTION AND ABNORMALITIES IN DIABETES}

\section{Mitochondria in type 1 diabetes}

Though mitochondria are not at the center of T1DM pathogenesis, previous observations have shown mitochondrial perturbation in different tissues in animal models (Shen et al., 2004; Bugger et al., 2009; Munusamy et al., 2009). Shen and coworkers discovered impaired mitochondrial function and increased oxidative stress in the heart of OVE26 mouse model with T1DM (Shen et al., 2004). Bugger and coworkers discovered that diabetes impacted mitochondrial functions differently in different tissues of T1DM Akita mice (Bugger et al., 2009). Munusamy and coworkers found that renal mito- chondrial complex III was selectively altered in the early stage of streptozotocin (STZ)-induced T1DM in diabetic rats, which they state may partly contribute to pathogenesis of diabetic nephropathy (Munusamy et al., 2009).

\section{Mitochondria in type 2 diabetes}

T2DM is characterized by impaired insulin release in pancreatic $\beta$-cells and IR in target tissues (muscle, liver and adipose). Cumulative evidence implicate that mitochondria play an important role in both processes, and mitochondrial dysfunction may be central to the pathogenesis of T2DM (Lowell and Shulman, 2005). Below is a description of the mitochondrial functions in various T2DM affected tissues and mitochondrial perturbations observed in these tissues.

Insulin secretion tissue: pancreatic $\beta$-cells

Insulin is synthesized and stored in pancreatic $\beta$-cells and the secretion of insulin within these cells is controlled largely by metabolism of fuels, foremostly blood glucose in the cells (Maechler et al., 2010). Mitochondria play a key role in the process of glucose-stimulated insulin secretion (GSIS) (Maechler and Wollheim, 2001; Maechler et al., 2006; Wiederkehr and Wollheim, 2006). In GSIS, mitochondria use the glucose-derived carbon to produce ATP which leads to an increase in the ATP/ADP ratio, which promotes the closure of the ATP-sensitive $\mathrm{K}^{+}$channel. The closure of this channel depolarizes of the plasma membrane and causes voltage-gated calcium channels to open, leading to calcium influx and then insulin secretion. Besides ATP, some metabolic messengers derived from mitochondria, such as glutamate, GTP, cAMP and NADPH, also promote the GSIS process. In summary, mitochondria take centre stage in the control of insulin secretion in response to glucose fluctuation, so it is reasonable that mitochondrial dysfunction in the pancreatic $\beta$-cells would impair insulin secretion, in turn leading to diabetes.

Functional and morphological modifications of mitochondria in the pancreatic islets or pancreatic $\beta$-cells were observed in T2DM patients and animal models. Anello and coworkers observed reduced insulin secretion, lower ATP levels, impaired mitochondrial membrane potential and increased mitochondrial density volume in pancreatic islets of T2DM patients (Anello et al., 2005). Increases in shorter and swollen mitochondria have been observed in the $\beta$-cells from Zucker diabetic fatty rat model (ZDF rat, a model of obesity, IR, and diabetes) (Bindokas et al., 2003). All these results indicate a key role for mitochondria in the pathology of islets in T2DM.

Target tissues of insulin action: skeletal muscle, adipose and liver

Though dysfunction of pancreatic $\beta$-cells and IR are funda- 
mental abnormalities seen in T2DM, several lines of evidence indicate that IR occurs preceding $\beta$-cell dysfunction (Lowell and Shulman, 2005). IR is defined as impairment in the ability of insulin to exert its effect on glucose and lipid metabolism in target tissues (Turner and Heilbronn, 2008). IR exerts different effects in different tissues: it reduces glucose uptake in muscle and adipose tissue whereas in liver results in reduced glycogen synthesis and inadequate suppression of glucose production and release into the blood. Despite intensive research, the mechanisms underlying IR are not fully understood, some studies have suggested that defects in mitochondrial function may play an important role in pathogenesis of IR and T2DM (Kim et al., 2008; Sivitz and Yorek, 2009). Here we will elucidate the function of mitochondria in three IR affected tissues: skeletal muscle, adipose and liver.

\section{Skeletal Muscle}

Skeletal muscle is the largest insulin-sensitive tissue and is the source for more than $80 \%$ of insulin-stimulated glucose uptake in human (Patti and Corvera, 2010), thus skeletal muscle is the predominant site of IR in T2DM (Mogensen et al., 2007).

Mitochondria are extremely important for skeletal muscle, given the high energy demand for muscle contraction. Two types of mitochondria exist in skeletal muscle: one type subsarcolemmal mitochondria (SSM), are clustered in proximity to the sarcolemma and appear round and dense in electron micrograph; the other type intermyofibrillar mitochondria (IFM), are embedded among the myofibrils and appear paler and lighter in the electron micrograph (Hood, 2001; Duchen, 2004; Ritov et al., 2005). The different pools of mitochondria have different functions in skeletal muscle: IFM provide most of energy for muscle contraction, while SSM generate ATP for membrane functions, including ion-exchange, substrate transport, protein synthesis and cell signaling transduction (Ritov et al., 2005). Therefore SSM play an important role in the action of insulin, and defects in SSM contribute to the pathogenesis of IR and T2DM. This has been observed as deficiencies of SSM in the muscle of T2DM and obese volunteers (Ritov et al., 2005). However, Chomentowski and coworkers found contradicting results where SSM were unaffected but the numbers of IFM decreased in muscle from IR subjects and T2DM patients (Chomentowski et al., 2011). The reason for these discrepancies between studies may be related to different methods in counting mitochondrial populations and differences in the selection of control subjects.

Several studies regarding skeletal muscle mitochondria provided evidence for aberrant muscle mitochondrial function in IR subjects and T2DM patients. Kelley and coworkers discovered reduced activity of $\mathrm{NADH}$ oxidoreductase and citrate synthase in the muscle mitochondria of T2DM volunteers compared to lean volunteers. They also observed smaller mitochondria and other changes in mitochondrial morphology in the T2DM volunteers (Kelley et al., 2002). Mogensen and coworkers discovered that respiratory function per mitochondrion was reduced in the skeletal muscle of T2DM patients compared with obese, nondiabetic subjects (Mogensen et al., 2007). Two microarray studies also showed decreased expression of sets of genes involved in OXPHOS and mitochondrial biogenesis in the muscle of diabetic subjects (Mootha et al., 2003; Patti et al., 2003).

Skeletal muscle mitochondrial dysfunction has also been observed in the IR offspring of T2DM parents (Petersen et al., 2004; Morino et al., 2005; Befroy et al., 2007). Petersen and coworkers observed that mitochondrial phosphorylation was reduced by $30 \%$ in the muscle of IR offspring, indicating impaired mitochondrial activity (Petersen et al., 2004). Morino and coworkers found that mitochondrial density was reduced by $38 \%$ in the muscle of IR offspring, which would account for the decrease in mitochondrial functions and activity (Morino et al., 2005). These inherited defects in the activity of mitochondria would likely decrease the rate of muscle mitochondrial substance oxidation in these progeny decreasing lipid oxidation and accumulating fatty acid metabolites, this in turn could impair insulin signaling at the level of insulin receptor substrate 1 and cause the IR (Befroy et al., 2007).

The reduced activities of the mitochondrial oxidative enzymes, lowered expression of mitochondrial OXPHOS proteins, and alterations in mitochondrial number, density, morphology and subcellular distribution in the muscle of T2DM patients and IR offspring seem to indicate the importance role of mitochondrial defects. However, Boushel observed no difference in oxidative phosphorylation and electron transport capacity between T2DM and healthy control subjects, when normalized for mitochondrial DNA content or citrate synthase activity, and attributed the observed defects in mitochondrial function in the muscle of T2DM to lower mitochondrial content (Boushel et al., 2007).

Though dysfunction in muscle mitochondria was observed in T2DM patients and their first-degree IR offspring, the potential mechanisms by which impaired muscle mitochondrial function could result in IR and T2DM is still under debate, and whether the observed mitochondrial dysfunction is the cause or the result of IR and T2DM remains controversial.

\section{Adipose}

Adipose tissue acts as a regulator of energy balance and glucose homeostasis through storage and turnover of triglycerides, and the secretion of adipokines and peptide hormones which affect food intake and energy expenditure (Rosen and Spiegelman, 2006; Guilherme et al., 2008). During feeding, adipose tissue accounts for $10 \%-15 \%$ of insulinstimulated glucose uptake after a meal (as mentioned above skeletal muscle is the main user of this glucose), and stores excess energy in the form of triglyceride. During fasting, triglyceride is hydrolyzed into fatty acids, lipolysis, which is 
transported into other tissues and oxidized for energy production in the mitochondria. Mitochondria play an important role in both processes: synthesis and storage of triglycerides in adipose mitochondria; and oxidation of fatty acids into energy in the mitochondria of other tissues.

Experimental evidence has linked adipose mitochondrial defects with obesity and T2DM in animal models. Choo and coworkers found that the levels of several key proteins of the mitochondrial respiratory chain, cellular mitochondrial DNA content and mitochondrial number were reduced in adipocytes of diabetic $\mathrm{db} / \mathrm{db}$ mice, but not in other tissues or in the ob/ob obese mice model. In addition, fatty acid oxidation and respiration were also dys-regulated in the adipocytes of diabetic mice (Choo et al., 2006). Wilson-Fritch and coworkers discovered that the abundance of $\sim 50 \%$ of the mitochondrial protein-encoded gene transcripts were altered in white adipocytes derived from epididymal fat pads of ob/ob mice when compared with related cells from C57BL/6J mice. Normal expression of those genes was recovered when treated with Rosiglitazone (an insulin sensitizer which binds to the PPAR receptors in fat cells and makes the cells more responsive to insulin). Along with the modifications in expression of the mitochondrial protein genes, fatty acid oxidation and oxygen consumption in mitochondria was increased in adipose treated with Rosiglitazone (Wilson-Fritch et al., 2004). The sum of the above results indicate that mitochondrial dysfunction in adipose tissue is correlated with T2DM. Further studies in human adipose would clarify the interaction between mitochondrial function and IR.

\section{Liver}

The liver plays a key role in maintaining glucose homeostasis: via storage of glucose as glycogen or conversion of glucose to lipid, for export and storage in adipose tissue during feeding; and via catabolism of glycogen, synthesis of glucose from noncarbohydrate sources such as amino acids (gluconeogenesis) and ketogenesis in the fasting state (Patti and Corvera, 2010). These systems of glucose homeostasis are modulated by insulin and other hormones, which regulate insulin signaling and gene expression, and in turn lead to inhibition or stimulation in glucose production. Mitochondria affect both processes in liver tissue through glucose metabolism and gluconeogenesis.

As there is a strong association between lipid accumulation in liver tissues and IR (Kotronen et al., 2008), and since mitochondria play a key role in the lipid metabolism, it is reasonable that liver mitochondria play a crucial role in the physiopathology of IR. Previous investigations observed alterations of liver mitochondrial morphology in the Ren2 rat model of IR and hypertension (Kim et al., 2008) and high-fat diet fed SD rats (Lieber et al., 2004). Vial and coworkers discovered that mitochondrial respiration was impaired in intact liver cells as well as in mitochondria isolated from rats that were fed with a high-fat diet for 8 weeks and presented with IR (Vial et al., 2010). Satapati and coworkers observed impaired hepatic mitochondrial fat oxidation in the ZDF rat (Satapati et al., 2008). These results suggest hepatic lipid accumulation and IR in liver tissues are ultimately linked to mitochondrial dysfunction.

\section{Mitochondria in diabetes complications}

Sustained hyperglycemia, a key feature of diabetes, damages vasculature throughout the body resulting in many chronic devastating macrovascular and microvascular complications. Macrovascular complications include heart disease, stroke and peripheral vascular disease, whereas microvascular complications affect the organs that are heavily dependent on their microvasculature supply namely, eyes, kidneys, and nerves (Santos et al., 2010).

It is important that cells are able to maintain glucose homeostasis when exposed to hyperglycemic conditions by reducing the transport of glucose inside the cells. However, certain cell groups that are directly affected by diabetes complications (including the retinal capillary endothelial cells, mesangial cells in the renal glomeruli, and neuronal and Schwann cells in peripheral nerves) are unable to decrease glucose concentration, and are thus susceptible to damage (Forbes et al., 2008).

Though independent biochemical pathways are involved in the pathogenesis of hyperglycemia-induced damage (increased glucose flux through the aldose reductase pathway, increased formation of glucose-derived advanced glycation end products, glucose-induced activation of protein kinase $\mathrm{C}$ isoforms, and increased hexosamine pathway activity) (Nishikawa et al., 2000; Brownlee, 2005; Forbes et al., 2008), a unified mechanism was proposed that overproduction of ROS by mitochondria in response to chronic hyperglycemia leading to oxidative stress and activating several stress-response pathway may be the major contributor to pathogenesis in complications from diabetes (Nishikawa et al., 2000; Brownlee, 2005; Nishikawa and Araki, 2007; Forbes et al., 2008). Besides that, mitochondrial pathway is also involved in cell apoptosis via releasing proteins that are involved in the apoptotic cascade, such as cytochrome $\mathrm{c}$ and apoptosis inducing factor. From this viewpoint, mitochondria play an important role in the pathology of diabetes complications. Below we discuss mitochondrial perturbations observed in different tissues affected by diabetes complications.

Heart

Diabetes cardiomyopathy is a recognized complication of diabetes leading to increased risk of heart failure and death. Previous reports showed that diabetes directly affected the function of cardiac mitochondria (Bugger and Abel, 2010). Boudina and coworkers investigated heart mitochondrial 
function in heart muscle fibers from $\mathrm{db} / \mathrm{db}$ diabetic mice compared with controls. They showed that the mitochondrial oxidative capacity was reduced despite increased mitochondrial proliferation. In addition, they also discovered a decrease in the F1 $\alpha$-subunit of ATP synthase and an increase in fatty acid induced proton leak mediated by activation of uncoupling proteins (UCP) (Boudina et al., 2007). These results indicated that mitochondrial energetics were impaired in the heart of $\mathrm{db} / \mathrm{db}$ mice. Mariappan and coworkers discovered that nuclear factor kappa-B (NF-KB) induced oxidative stress and contributed to mitochondrial and cardiac dysfunction in $\mathrm{db} / \mathrm{db}$ mice (Mariappan et al., 2009). Mitochondrial abnormality was also observed in T1DM Akita mouse hearts (Bugger et al., 2008).

Kidney

Diabetic nephropathy is one of the main causes of morbidity and mortality in patients with diabetes (Phillips and Molitch, 2002). Approximately $40 \%$ of T2DM patients will develop diabetic kidney disease, without effective intervention (Lewis and Lewis, 2003). Kartha and coworkers detected an increase in NADPH oxidase-4 (NOX-4) and decrease in superoxide dismutase 2 (SOD2) expression in mitochondria together with an increase in mitochondrial protein tyrosine nitration in the kidney tissue of diabetic mice fed on a high calorie and fat diet (Kartha et al., 2008). These results implied that mitochondrial function was impaired in the kidney of diabetic mice (Kartha et al., 2008).

\section{Retina}

Diabetic retinopathy (DR), the leading cause of acquired blindness in young adults, is also a major complication of diabetes (Santos et al., 2011). Retinal mitochondrial biogenesis is impaired in STZ-induced diabetic wild-type mice compared with STZ-induced diabetic mice overexpressing MnSOD (Santos et al., 2011; Tewari et al., 2012). Overexpression of MnSOD protects the retina from diabetes induced oxidative stress and the development of DR (Kanwar et al., 2007). High glucose has been reported to disrupt mitochondrial morphology and influence mitochondrial function in retinal endothelial cells (Trudeau et al., 2010). In all, mitochondria play an important role in the development of DR.

\section{Nerve}

Diabetic neuropathy is the most common complication of diabetes and affects the sensory and autonomic nervous systems and imposes a great burden on the health of the patient (Leinninger et al., 2006b). There is growing evidence that oxidative stress is the key pathological process that induces nerve damage in diabetes cases (Verkhratsky and Fernyhough, 2008), and mitochondria are specific targets of oxidative stress-induced injury (Schmeichel et al., 2003). Mitochondria are essentially important for neuronal function because $90 \%$ of the ATP required for the normal functioning of neurons is provided by mitochondria. Previous studies showed that diabetes altered the activity of brain mitochondria isolated from aged Goto-Kakizaki (GK) diabetic rats (Moreira et al., 2005a) and STZ diabetic rats (Moreira et al., 2005b). Abnormalities in mitochondrial ultrastructure and changes in mitochondrial number and size were also observed in the sensory fibers of the dorsal root and in the sympathetic ganglia in human and animal models (Fernyhough et al., 2010; Chowdhury et al., 2012). Mitochondrial injury was also observed in neurons treated with high glucose (Leinninger et al., 2006a; Yu et al., 2008). Leinninger and coworkers observed that mitochondria in dorsal root ganglia (DRG) neurons undergo hyperglycemia-mediated injury through BAX, Bim, and mitochondrial fission protein Drp1 (Leinninger et al., 2006a). Yu and coworkers found that high glucose induces mitochondrial fragmentation through elevated production of ROS (Yu et al., 2008). All these observations highlighted the importance of mitochondrial impairment in diabetic neuropathy.

\section{MITOCHONDRIAL PROTEOMICS APPLIED TO DIABETES RESEARCH}

As diabetes is a complicated metabolic disorder that influences many tissues, and mitochondria dysfunction has been described in these tissues, there have been many research attempts to characterize differentially expressed mitochondrial proteins in various tissues connected to diabetes pathology. Proteomics is an attractive tool for the study of this complicated disease, since it allows researchers to globally compare the protein expression profile and protein modifications in tissues, cells or organelles from normal and diseased states. Below we discuss the technologies used in mitochondrial proteome research and the application of mitochondrial proteomics to elucidate the mechanisms in diabetes (Table 1).

\section{Comparative mitochondrial proteomic technologies}

The basic procedure for comparative mitochondrial proteomics research includes mitochondrial isolation, large-scale separation of mitochondrial proteins, and protein identification and quantification by mass spectrometry.

Mitochondrial isolation methods for proteomic analysis

The most effective method for mitochondrial isolation is centrifugation though several other techniques, such as free flow electrophoresis (Zischka et al., 2003), have been applied. A crude mitochondrial fraction is harvested using differential centrifugation involving low speed centrifugation (600-800 g) 


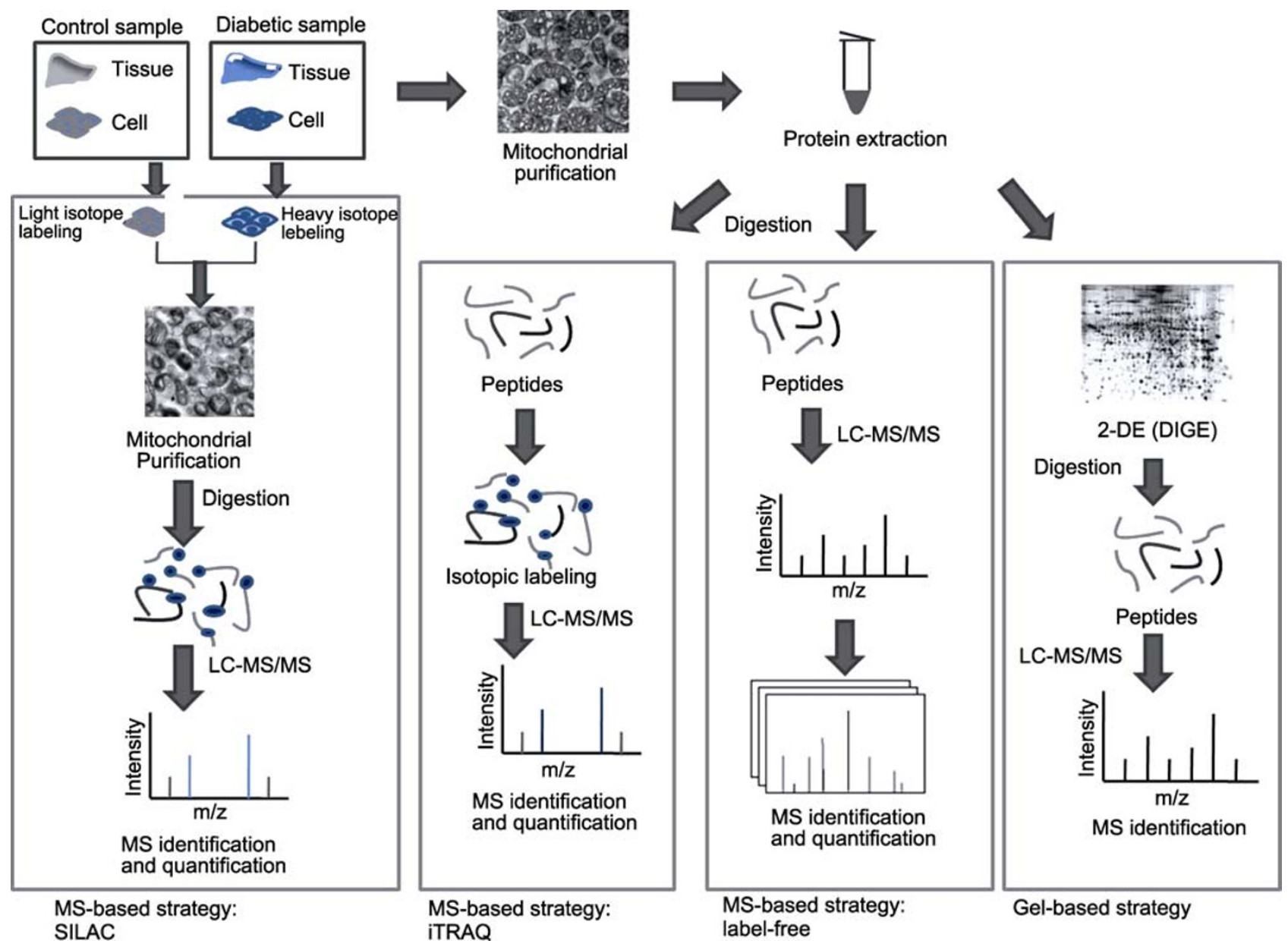

Figure 1. Strategies used in comparative mitochondrial proteomics

to remove nucleus and cell debris, and then again at high speed $(10,000-25,000 \mathrm{~g})$. However, crude mitochondrial fractions contain many contaminations from other subcellular organelles, such as endoplasmic reticulum, lysosomes. To reduce these contaminants, mitochondria are further purified using density gradient centrifugation with sucrose (Rezaul et al., 2005), nycodenz (Li et al., 2009; Cui et al., 2010), percoll (Pagliarini et al., 2008) or metrizamide (Taylor et al., 2003). However, complete purification is virtually impossible despite the best efforts of researchers and that fact that these contaminations may only transiently exist in the mitochondria.

\section{Gel-based proteomic strategies}

The quantitative strategies for mitochondrial proteomics research include gel-based strategies and MS-based strategies (gel-free strategies). The standard gel-based strategy is two-dimensional gel electrophoresis (2-DE) (Rabilloud et al., 2010) in which proteins are separated by their isoelectric points on immobilized $\mathrm{pH}$ gradient strips, and then by size on conventional SDS-PAGE. The gels are then stained with coomassie brilliant blue, sliver, or fluorescent dyes SYPRO
Ruby (Patton, 2000) to visualize the protein spots in the gel. Gel images are analyzed with bioinformatic tools to find the differentially expressed protein spots, subsequently these protein spots are picked from the gel, in-gel digested with protease, and then subjected to MS analysis to identify the protein. Differential in-gel electrophoresis (DIGE) is a modified version of 2-DE which labels protein samples with different fluorescence tags (Cy2, Сy3, Cy5) then mixes them together and runs them on the same two-dimensional gel (D'Hertog et al., 2006). As pooled samples behave as an internal standard for quantification, DIGE reduces inter-gel variation and false positives in quantification. Although gel-based strategies can separate thousands of proteins in one gel and offer antibody-free technique for detection of protein PTM (Rabilloud et al., 2010), they suffer shortcomings when analyzing hydrophobic, basic and low-abundant mitochondrial proteins.

\section{MS-based proteomic strategies}

To overcome the limitation of gel-based strategies, more and more researchers have applied MS-based quantitative 
strategies to compare differentially expressed mitochondrial proteins. The MS-based quantitative strategies, including stable isotope-labeling quantification and label-free quantification, rely on LC-MS/MS data to perform the comparison. Stable isotope-labeling strategies perform relative quantification by introducing an identical chemical tag of different mass to proteins in different samples. Commonly applied technologies in mitochondrial proteomics research include SILAC, stable isotope labeling by amino acids in cell culture (Ong et al., 2002), and iTRAQ, isobaric tags for relative and absolute quantification (Ross et al., 2004). SILAC acts by metabolically incorporating the stable isotope amino acids into proteins at the cell culture level, and then mitochondria are purified from combinations of cell populations that are labeled with different isotopes. Though SILAC is a simple and accurate quantitative proteomic tool, it could only be used in cell culture level and is not applicable to samples from tissues. iTRAQ supplies this gap by incorporating the stable isotope tags at the peptide level. In iTRAQ, mitochondrial proteins from different samples are digested into peptides, after that, peptides are labeled separately with different isotopic variants of ITRAQ reagents and then combined for LC-MS/MS analysis. These stable isotope-labeling approaches have advantages in quantification accuracy and reproducibility when comparing protein changes in complex mitochondrial samples. However, most labeling-based quantification approaches suffer potential limitations, including limited linear dynamic range, high cost of the labeling reagents and increased time and complexity of sample preparation. Furthermore, only ITRAQ allows compare multiple samples (up to eight) at the same time. The other labeling methods could only compare protein changes between two or three different samples.

Label-free quantification compares the mass spectrometric signal intensity or chromatographic peak area of peptide precursor ions that belong to a particular protein, or by comparing the number of MS/MS spectra that identify peptides of a given protein (Zhu et al., 2010). These approaches are less accurate compared to stable isotope-labeling approaches because all the systematical and non-systematical variations between experiments are present in the data; however, they provide higher dynamic range of quantification and deeper proteome coverage (Bantscheff et al., 2007). Moreover, there is no limit to the number of samples that can be compared. Therefore, label-free quantification approaches are advantageous for investigating large and global protein changes between different samples. A brief summary of the strategies used in mitochondrial proteomics research is shown in Fig. 1.

Proteomic techniques for protein post-translational modifications (PTM) analysis

As post-translational modifications (PTM) of mitochondrial proteins have been reported to regulate in mitochondrial functions in diabetes, several studies are conducted to investigate the PTMs of mitochondrial proteins using proteomic tools (Turko et al., 2003; Kartha et al., 2008; Hu et al., 2009; Wang et al., 2010). Global analysis of protein phosphorylation, one of the most prominent PTM, is conducted by mass spectrometric strategies in combined with phospho-specific enrichment methods, such as immunoaffinity with anti-pY antibody, immobilized metal ion affinity chromatography (IMAC) and titanium dioxide $\left(\mathrm{TiO}_{2}\right)$ chromatography (Eyrich et al., 2011). Protein tyrosine nitrosylation, a common post-translational modification occurred under conditions of oxidative stress (Greenacre and Ischiropoulos, 2001), is traditionally analyzed in a proteomic strategy combined 2-DE, western blot and mass spectrometry (Turko et al., 2003; Wang et al., 2010). Now, new approaches were also developed for analysis of S-nitrosylated proteins and/or the identification of specific sites of nitrosylation (Lopez-Sanchez et al., 2012). Glycosylation was analyzed with glycoprotein or glycopeptides enrichment techniques, coupled with multidimensional chromatographic separation and mass spectrometry (Pan et al., 2010). Further developments in proteomic technique to analyze protein PTMs could provide more information about the mitochondrial functions in diabetes.

\section{Mitochondrial proteomics in T1DM}

Currently there is no published mitochondrial proteomic data on mitochondrial alterations or development of T1DM based on human tissues because of the limited tissue available. The majority of the mitochondrial proteome research has been conducted in animal models exhibiting T1DM, including STZ-induced T1DM mice/rats, spontaneously genetically diabetic Akita mouse and OVE26 T1DM mice.

Several proteomic investigations on the heart in T1DM mouse models found an increased expression of mitochondrial protein involved in fatty acid oxidation and oxidative stress (Shen et al., 2004; Hamblin et al., 2007), probably because of increasing mitochondrial biogenesis (Shen et al., 2004). A subsequent mitochondrial proteomic study combining isotope labeling and 2-DE from STZ-induced diabetic rat hearts confirmed that proteins involved in fatty acid oxidation were increased, with a modest decrease in electron transport proteins, and little change in tricarboxylic acid (TCA) cycle proteins (Turko and Murad, 2003). However, there are two distinct mitochondrial subpopulations in the cardiac myocytes, SSM and IMF, similar to that found in skeletal muscle. The two populations of mitochondria response differently to physiological stimuli including obesity, diabetes, aging, fasting, apoptosis, and ischemia-reperfusion injury (Lesnefsky et al., 2001; Suh et al., 2003; Ritov et al., 2005; Mollica et al., 2006). John M. Hollander's research group investigated thoroughly the differential response of the two populations of mitochondria in both T1DM and T2DM, using both biochemical and proteomic tools, and thus improved our under- 
Table 1 Summary of mitochondrial alterations in diabetes affected tissues and the proteomics application used to study them

\begin{tabular}{|c|c|c|c|c|c|}
\hline Diabetic model & Tissues/cells & $\begin{array}{l}\text { Alterations of mitochondrial } \\
\text { physiology }\end{array}$ & $\begin{array}{l}\text { Alterations of mitochondrial protein } \\
\text { expression }\end{array}$ & Proteomic tools & Reference \\
\hline \multicolumn{6}{|l|}{ Type 1 diabetes } \\
\hline $\begin{array}{l}\text { OVE26 diabetic } \\
\text { mice }\end{array}$ & Heart & $\begin{array}{l}\uparrow \text { Mitochondrial area and } \\
\text { number } \\
\downarrow \text { Respiration control ratio } \\
\text { and state } 3 \text { respiration rate }\end{array}$ & $\uparrow$ Fatty acid oxidation proteins & & $\begin{array}{l}\text { Shen et al., } \\
2004\end{array}$ \\
\hline $\begin{array}{l}\text { STZ-induced } \\
\text { diabetic rats }\end{array}$ & $\begin{array}{l}\text { Heart mitochon- } \\
\text { dria }\end{array}$ & & $\begin{array}{l}\uparrow \text { Fatty acid oxidation proteins } \\
\downarrow \text { Electron transport proteins }\end{array}$ & $\begin{array}{l}\text { Isotopic } \\
\text { labeling, 2-DE }\end{array}$ & $\begin{array}{l}\text { Turko and } \\
\text { Murad, } \\
2003\end{array}$ \\
\hline $\begin{array}{l}\text { STZ-induced } \\
\text { diabetic mice }\end{array}$ & $\begin{array}{l}\text { Heart SSM and } \\
\text { IFM }\end{array}$ & & $\begin{array}{l}\downarrow \text { Fatty acid oxidation IFM proteins } \\
\downarrow \text { Electron transport IFM proteins } \\
\downarrow \text { IFM proteins involved in protein } \\
\text { import and substrate transport }\end{array}$ & iTRAQ, DIGE & $\begin{array}{l}\text { Baseler et } \\
\text { al., } 2010\end{array}$ \\
\hline $\begin{array}{l}\text { STZ-induced } \\
\text { diabetic rats }\end{array}$ & $\begin{array}{l}\text { Mitochondria } \\
\text { from DRG sen- } \\
\text { sory neuron }\end{array}$ & $\begin{array}{l}\downarrow \text { Respiration chain activity } \\
\downarrow \text { mitochondrial membrane } \\
\text { potential } \\
\downarrow \text { ROS }\end{array}$ & $\begin{array}{l}\downarrow \text { Respiratory chain components of } \\
\text { mitochondria }\end{array}$ & $\begin{array}{l}\text { SILAC-labeled } \\
\text { Schwann cells } \\
\text { as internal } \\
\text { standard }\end{array}$ & $\begin{array}{l}\text { Akude et } \\
\text { al., } 2011\end{array}$ \\
\hline $\begin{array}{l}\text { Akita diabetic } \\
\text { mice }\end{array}$ & $\begin{array}{l}\text { Mitochondria } \\
\text { from liver, heart, } \\
\text { brain, kidney }\end{array}$ & $\begin{array}{l}\downarrow \text { State } 3 \text { respiration, ATP } \\
\text { synthesis, mitochondrial } \\
\text { cristae density in cardiac } \\
\text { mitochondria }\end{array}$ & $\begin{array}{l}\uparrow \text { Fatty acid oxidation protein in } \\
\text { mitochondria from brain, heart and } \\
\text { kidney } \\
\downarrow \text { TCA cycle proteins in cardiac } \\
\text { mitochondria } \\
\uparrow \text { Oxidative phosphorylation } \\
\text { proteins in liver mitochondria }\end{array}$ & Label free & $\begin{array}{l}\text { Bugger et } \\
\text { al., } 2009\end{array}$ \\
\hline \multicolumn{6}{|l|}{ Type 2 diabetes } \\
\hline $\mathrm{db} / \mathrm{db}$ mice & $\begin{array}{l}\text { Heart SSM and } \\
\text { IFM }\end{array}$ & $\begin{array}{l}\downarrow \text { Size and internal complexity } \\
\text { of SSM } \\
\downarrow \text { State } 3 \text { respiration rates, } \\
\text { electron transport chain } \\
\text { activities, and mitochondrial } \\
\text { membrane potential of SSM } \\
\uparrow \text { Oxidative damage in SSM }\end{array}$ & $\begin{array}{l}\downarrow \text { Mitochondrial inner membrane } \\
\text { proteins, such as electron transport } \\
\text { chain, ATP synthesis, and mito- } \\
\text { chondrial protein import machinery }\end{array}$ & iTRAQ & $\begin{array}{l}\text { Dabkowski } \\
\text { et al., } 2010\end{array}$ \\
\hline $\begin{array}{l}\text { Goto-Kakizaki } \\
\text { rats }\end{array}$ & $\begin{array}{l}\text { Liver } \\
\text { mitochondria }\end{array}$ & & $\begin{array}{l}\uparrow \text { Proteins that involved in the TCA } \\
\text { cycle, OXPHOS, } \beta \text {-oxidation } \\
\downarrow \text { proteins involved in anti-apoptosis } \\
\text { and anti-oxidative stress }\end{array}$ & Label free & $\begin{array}{l}\text { Deng et al., } \\
2009\end{array}$ \\
\hline $\begin{array}{l}\text { High calorie and } \\
\text { fat-induced } \\
\text { diabetic mice }\end{array}$ & $\begin{array}{l}\text { Kidney } \\
\text { mitochondria }\end{array}$ & & $\begin{array}{l}\uparrow \text { Mitochondrial protein tyrosine } \\
\text { nitration }\end{array}$ & $2-\mathrm{DE}$ & $\begin{array}{l}\text { Kartha et } \\
\text { al., } 2008\end{array}$ \\
\hline $\mathrm{db} / \mathrm{db}$ mice & $\begin{array}{l}\text { Heart } \\
\text { mitochondria }\end{array}$ & & $\begin{array}{l}\uparrow \text { Mitochondrial protein tyrosine } \\
\text { nitration }\end{array}$ & 2-DE & $\begin{array}{l}\text { Wang et al., } \\
2010\end{array}$ \\
\hline $\begin{array}{l}\text { Type } 2 \text { diabetic } \\
\text { patients }\end{array}$ & Muscle & & $\begin{array}{l}\downarrow \text { Phosphorylation of ATPsynthase } \\
\beta \text {-subunit }\end{array}$ & 2-DE & $\begin{array}{l}\text { Hojlund et } \\
\text { al., } 2003\end{array}$ \\
\hline
\end{tabular}

Abbreviations: 2-DE: two-dimensional electrophoresis; DIGE, differential in-gel electrophoresis; SILAC, stable isotope labeling by amino acids in cell culture; ITRAQ, isobaric tags for relative and absolute quantitation; SSM: subsarcolemmal mitochondria; IFM: intermyofibrillar mitochondria; DRG: dorsal root ganglia.

standing of the role of different mitochondrial populations in the pathogenesis of diabetic cardiomyopathy (Dabkowski et al., 2009; Baseler et al., 2010; Dabkowski et al., 2010). Baseler and coworkers conducted the first mitochondrial proteomic research in the heart of STZ-induced diabetic mice to investigate the different response of the two mitochondrial populations to T1DM. After separating the IFM and SSM populations from the heart, iTRAQ and DIGE were applied to find the differentially expressed proteins. They found that a number of changes occurring preferentially in IFM, including a decreased abundance of fatty acid oxidation and electron transport chain proteins. Interestingly, three proteins involved in mitochondrial protein import and substrate transport (HSP70, ANT1, and mitochondrial phosphate carrier) were preferentially decreased in IFM. Further investigation showed that there is a selective deficiency in the ability of IFM to transport mitochondrial protein into mitochondrial inner membrane (Baseler et al., 2010).

Akude and coworkers quantitatively investigated the changes in the mitochondrial proteome in DRG sensory neurons from STZ-induced diabetic rats by using SILAC-labeled Schwann cells as internal standards. They 
discovered that the respiratory chain components of mitochondrial proteome were down-regulated in the DRG of diabetic rats. Consistent with decreased protein expression and impaired respiratory chain activity, as demonstrated by reduced mitochondrial membrane potential and reduced respiratory chain derived ROS generation (Akude et al., 2011).

Bugger and coworkers conducted a comprehensive comparison of mitochondrial proteomes across four tissues (liver, brain, heart and kidney) from wild-type and T1DM Akita mice, using label-free proteome analysis. They discovered that the remodeling of the mitochondrial proteome by diabetes was tissue specific: fatty acid oxidation (FAO) proteins were less abundant in liver mitochondria, whereas FAO protein content increased in mitochondria from all other tissues. Kidney mitochondria showed induction of TCA cycle enzymes, whereas TCA cycle proteins were decreased in cardiac mitochondria. In addition, the expression of OXPHOS proteins was increased in liver mitochondria, whereas mitochondria of the other tissues were unaffected. Mitochondrial respiration, ATP synthesis, and morphology were unaffected in liver and kidney. In contrast, state 3 respiration, ATP synthesis, and mitochondrial cristae density decreased in cardiac mitochondria. These results indicate that diabetes affected mitochondria differently in different tissues (Bugger et al., 2009). This tissue-specific remodeling of mitochondria in diabetes underscored the importance in applying proteomic tools to study the role of mitochondria in pathogenesis of diabetes.

\section{Mitochondrial proteomics in T2DM}

The pathogenesis of T2DM involves the alteration of mitochondrial proteins in various tissues including pancreatic islets, liver, heart, and kidney. Several mitochondrial proteome studies have been conducted in these tissues. Mitochondrial pathways of metabolism and stress response in diabetes stimulations could be mapped with proteomic tools (Gregersen et al., 2012). Lu and coworkers investigated the changes of mitochondrial morphology and function during the progression from insulin resistance to T2DM in the islets of transgenic MKR mice. They discovered that decreased mitochondrial function and abnormal morphology occurred before hyperglycemia onset, and that mitochondrial dysfunction played important role in the progression to T2DM. Further investigations of the protein changes with ITRAQ uncovered 36 mitochondrial proteins that were differentially expressed, many of which were mitochondrial inner membrane proteins of the electron transport chain (Lu et al., 2009).

Deng and coworkers conducted a comprehensive mitochondrial proteome investigation on liver mitochondria from spontaneous diabetic GK rats before and after they were rendered diabetic. They identified 1091 mitochondrial proteins, 228 phosphoproteins and 355 hydroxyproteins in liver mitochondria. Semi-quantitative analysis revealed that the expression of mitochondrial proteins that were involved in $\beta$-oxidation, the TCA cycle, OXPHOS and other bioenergetic processes was up-regulated, whereas the expression of proteins involved in anti-apoptosis and anti-oxidative stress was down-regulated. Besides that, mitochondrial proteins were heavily hydroxylated during T2DM development, suggesting increased oxidative stress. All of the changes were correlated with the development of T2DM (Deng et al., 2010).

As mentioned above, cardiomyocytes consist of two populations of mitochondria, IFM and SSM, and the two populations respond differently to physiological stimuli. Recent results have shown that T1DM and T2DM influence mitochondrial populations differently. IMF was selectively impaired in the heart of T1DM mice (Baseler et al., 2010), however, SSM mitochondria were specifically affected in $\mathrm{db} / \mathrm{db}$ diabetic mice hearts (Dabkowski et al., 2010). SSM from $\mathrm{db} / \mathrm{db}$ hearts showed decreased size and internal complexity, while db/db IFM showed increased internal complexity. Db/db SSM also displayed decreased state 3 respiration rates, electron transport chain activities, ATP synthase activities, mitochondrial membrane potential, and increased oxidative damage. Proteomic analysis with iTRAQ revealed that T2DM had a greater impact on SSM than IFM. The expression level of mitochondrial inner membrane proteins, such as electron transport chain, ATP synthesis, and mitochondrial protein import machinery, was greatly decreased in SSM. We compared mitochondrial protein changes in normal vs. high-glucose treated INS-1 $\beta$ cells using SILAC and found that the expression of proteins involved in OXPHOS, substance metabolism, mitochondrial protein synthesis and cell death was significantly decreased (unpublished data).

Besides changes in mitochondrial protein expression, diabetes has been linked to post-translational modifications of mitochondrial proteins including proteins involved with phosphorylation, nitrosylation and O-linked glycosylation (O-GlcNAcylation). Højlund and coworkers identified potential biomarkers in the skeletal muscle of T2DM patients and found that the expression and phosphorylation of the ATP synthase $\beta$-subunit was altered, possibly accounting for the pathogenesis of T2DM (Hojlund et al., 2003). Kartha and coworkers detected an increase in mitochondrial protein tyrosine nitration in the kidney tissue of high calorie and fat diet-induced diabetic mice (Kartha et al., 2008). Protein tyrosine nitration was also observed in the mitochondria from diabetic mouse heart (Turko et al., 2003; Wang et al., 2010). Increased O-linked glycosylation was reported in mitochondrial proteins of caridiomyocytes that were exposed to high glucose. Increased mitochondrial protein O-GlcNAcylation is associated with impaired mitochondrial function, and reversal of O-GIcNAcylation with the overexpression of O-GIcNAcase restores mitochondrial function in cultured caridiomyocytes that are exposed to high glucose (Hu et al., 2009). Taken 
together, mitochondrial protein modifications have been linked with impaired mitochondrial function and the pathogenesis of diabetes. Future in depth proteomic analysis of protein modifications could provide important new insights into the pathogenesis of mitochondrial dysfunction in diabetes.

\section{FUTURE PERSPECTIVES AND CONCLUDING REMARKS}

In summary, increasing evidence has come to light implicating mitochondrial dysfunction in the pathogenesis of diabetes and its complications. This suggests that mitochondria have the potential to be targets for the treatment of diabetes (Moreira and Oliveira, 2011). Comparative mitochondrial proteomics in different tissues of diabetic animal models have gained insights into the pathogenesis of diabetes and its complications, thus could provide more information for the development of drugs for the treatment of diabetes. Though great progress has been made in mitochondrial proteomics in diabetes, most of these studies solely focused on protein expression, however, mitochondrial protein post-translational modifications, such as phosphorylation, also played crucial roles in mitochondrial functioning (Thomson, 2002; Pagliarini and Dixon, 2006) and mitochondrial perturbations (Graier et al., 2009). Further studies to examine the changes in mitochondrial protein post-translational modifications with proteomic tools in diabetes affected animal model tissues, could provide more information and increase our understanding of the pathogenesis of diabetes.

\section{ACKNOWLEDGEMENTS}

The authors would like to thank all of the members in our lab for their supports in preparation of the manuscript, and Dr. Elizabeth Ashforth for her critical reading and useful suggestions. This study was supported by the National Basic Research Program of China (Nos. 2010CB833703, 2012CB966803, 2011CB915501), the National Natural Science Foundation of China (Grant No. 90919047) and Novo Nordisk-CAS Research Foundation (No. NNCAS-2011-1). We apologize to the scientists who made contributions to the field, but have not been cited due to space limitations. The authors have no other relevant affiliations or financial involvement with any organization or entity with a financial interest in or financial conflict with the subject matter or materials discussed in the manuscript apart from those disclosed.

\section{ABBREVIATIONS}

2-DE, two-dimensional gel electrophoresis; DIGE, differential in-gel electrophoresis; DRG: dorsal root ganglia; GK,Goto-Kakizaki; GSIS: glucose-stimulated insulin secretion; IFM: intermyofibrillar mitochondria; IR, insulin resistance; ITRAQ, isobaric tags for relative and absolute quantitation; SILAC, stable isotope labeling by amino acids in cell culture; SSM: subsarcolemmal mitochondria; T1DM, type 1 dia- betes; T2DM, type 2 diabetes;

\section{REFERENCES}

Akude, E., Zherebitskaya, E., Chowdhury, S.K., Smith, D.R., Dobrowsky, R.T., and Fernyhough, P. (2011). Diminished superoxide generation is associated with respiratory chain dysfunction and changes in the mitochondrial proteome of sensory neurons from diabetic rats. Diabetes 60, 288-297.

Anello, M., Lupi, R., Spampinato, D., Piro, S., Masini, M., Boggi, U., Del Prato, S., Rabuazzo, A.M., Purrello, F., and Marchetti, P. (2005). Functional and morphological alterations of mitochondria in pancreatic beta cells from type 2 diabetic patients. Diabetologia 48, 282-289.

Bantscheff, M., Schirle, M., Sweetman, G., Rick, J., and Kuster, B. (2007). Quantitative mass spectrometry in proteomics: a critical review. Anal Bioanal Chem 389, 1017-1031.

Baseler, W.A., Dabkowski, E.R., Williamson, C.L., Croston, T.L., Thapa, D., Powell, M.J., Razunguzwa, T.T., and Hollander, J.M. (2010). Proteomic alterations of distinct mitochondrial subpopulations in the type 1 diabetic heart: contribution of protein import dysfunction. Am J Physiol Regul Integr Comp Physiol 300, R186-200.

Befroy, D.E., Petersen, K.F., Dufour, S., Mason, G.F., de Graaf, R.A., Rothman, D.L., and Shulman, G.I. (2007). Impaired mitochondrial substrate oxidation in muscle of insulin-resistant offspring of type 2 diabetic patients. Diabetes 56, 1376-1381.

Bindokas, V.P., Kuznetsov, A., Sreenan, S., Polonsky, K.S., Roe, M.W., and Philipson, L.H. (2003). Visualizing superoxide production in normal and diabetic rat islets of Langerhans. J Biol Chem 278, 9796-9801.

Boudina, S., Sena, S., Theobald, H., Sheng, X., Wright, J.J., Hu, X.X., Aziz, S., Johnson, J.I., Bugger, H., Zaha, V.G., et al. (2007). Mitochondrial energetics in the heart in obesity-related diabetes: direct evidence for increased uncoupled respiration and activation of uncoupling proteins. Diabetes 56, 2457-2466.

Boushel, R., Gnaiger, E., Schjerling, P., Skovbro, M., Kraunsoe, R., and Dela, F. (2007). Patients with type 2 diabetes have normal mitochondrial function in skeletal muscle. Diabetologia 50 , 790-796.

Brownlee, M. (2005). The pathobiology of diabetic complications: a unifying mechanism. Diabetes 54, 1615-1625.

Bugger, H., and Abel, E.D. (2010). Mitochondria in the diabetic heart. Cardiovasc Res 88, 229-240.

Bugger, H., Boudina, S., Hu, X.X., Tuinei, J., Zaha, V.G., Theobald, H.A., Yun, U.J., McQueen, A.P., Wayment, B., Litwin, S.E., et al. (2008). Type 1 diabetic akita mouse hearts are insulin sensitive but manifest structurally abnormal mitochondria that remain coupled despite increased uncoupling protein 3. Diabetes 57 , 2924-2932.

Bugger, H., Chen, D., Riehle, C., Soto, J., Theobald, H.A., Hu, X.X., Ganesan, B., Weimer, B.C., and Abel, E.D. (2009). Tissue-specific remodeling of the mitochondrial proteome in type 1 diabetic akita mice. Diabetes 58, 1986-1997.

Chan, D.C. (2006). Mitochondria: dynamic organelles in disease, aging, and development. Cell 125, 1241-1252.

Chomentowski, P., Coen, P.M., Radikova, Z., Goodpaster, B.H., and 
Toledo, F.G. (2011). Skeletal muscle mitochondria in insulin resistance: differences in intermyofibrillar versus subsarcolemmal subpopulations and relationship to metabolic flexibility. J Clin Endocrinol Metab 96, 494-503.

Choo, H.J., Kim, J.H., Kwon, O.B., Lee, C.S., Mun, J.Y., Han, S.S., Yoon, Y.S., Yoon, G., Choi, K.M., and Ko, Y.G. (2006). Mitochondria are impaired in the adipocytes of type 2 diabetic mice. Diabetologia 49, 784-791.

Chowdhury, S.K., Smith, D.R., and Fernyhough, P. (2012). The role of aberrant mitochondrial bioenergetics in diabetic neuropathy. Neurobiol Dis (In Press).

Cui, Z., Hou, J., Chen, X., Li, J., Xie, Z., Xue, P., Cai, T., Wu, P., Xu, T., and Yang, F. (2010). The profile of mitochondrial proteins and their phosphorylation signaling network in INS-1 beta cells. J Proteome Res 9, 2898-2908.

D'Hertog, W., Mathieu, C., and Overbergh, L. (2006). Type 1 diabetes: entering the proteomic era. Expert Rev Proteomics 3, 223-236.

Dabkowski, E.R., Baseler, W.A., Williamson, C.L., Powell, M., Razunguzwa, T.T., Frisbee, J.C., and Hollander, J.M. (2010). Mitochondrial dysfunction in the type 2 diabetic heart is associated with alterations in spatially distinct mitochondrial proteomes. Am J Physiol Heart Circ Physiol 299, H529-540.

Dabkowski, E.R., Williamson, C.L., Bukowski, V.C., Chapman, R.S., Leonard, S.S., Peer, C.J., Callery, P.S., and Hollander, J.M. (2009). Diabetic cardiomyopathy-associated dysfunction in spatially distinct mitochondrial subpopulations. Am J Physiol Heart Circ Physiol 296, H359-369.

Deng, W.J., Nie, S., Dai, J., Wu, J.R., and Zeng, R. (2010). Proteome, phosphoproteome and hydroxyproteome of liver mitochondria in diabetic rats at early pathogenic stages. Mol Cell Proteomics 9, 110-116.

Duchen, M.R. (2004). Mitochondria in health and disease: perspectives on a new mitochondrial biology. Mol Aspects Med 25, 365-451.

Eyrich, B., Sickmann, A., and Zahedi, R.P. (2011). Catch me if you can: mass spectrometry-based phosphoproteomics and quantification strategies. Proteomics 11, 554-570.

Fernyhough, P., Roy Chowdhury, S.K., and Schmidt, R.E. (2010). Mitochondrial stress and the pathogenesis of diabetic neuropathy. Expert Rev Endocrinol Metab 5, 39-49.

Forbes, J.M., Coughlan, M.T., and Cooper, M.E. (2008). Oxidative stress as a major culprit in kidney disease in diabetes. Diabetes $57,1446-1454$.

Graier, W.F., Malli, R., and Kostner, G.M. (2009). Mitochondrial protein phosphorylation: instigator or target of lipotoxicity? Trends Endocrinol Metab 20, 186-193.

Greenacre, S.A., and Ischiropoulos, H. (2001). Tyrosine nitration: localisation, quantification, consequences for protein function and signal transduction. Free Radic Res 34, 541-581.

Gregersen, N., Hansen, J., and Palmfeldt, J. (2012). Mitochondrial proteomics-a tool for the study of metabolic disorders. J Inherit Metab Dis.

Guilherme, A., Virbasius, J.V., Puri, V., and Czech, M.P. (2008). Adipocyte dysfunctions linking obesity to insulin resistance and type 2 diabetes. Nat Rev Mol Cell Biol 9, 367-377.

Hojlund, K., Wrzesinski, K., Larsen, P.M., Fey, S.J., Roepstorff, P., Handberg, A., Dela, F., Vinten, J., McCormack, J.G., Reynet, C., et al. (2003). Proteome analysis reveals phosphorylation of ATP synthase beta-subunit in human skeletal muscle and proteins with potential roles in type 2 diabetes. J Biol Chem 278, 10436-10442.

Hood, D.A. (2001). Invited Review: contractile activity-induced mitochondrial biogenesis in skeletal muscle. J Appl Physiol 90, 1137-1157.

Hu, Y., Suarez, J., Fricovsky, E., Wang, H., Scott, B.T., Trauger, S.A., Han, W., Oyeleye, M.O., and Dillmann, W.H. (2009). Increased enzymatic O-GICNAcylation of mitochondrial proteins impairs mitochondrial function in cardiac myocytes exposed to high glucose. J Biol Chem 284, 547-555.

Kanwar, M., Chan, P.S., Kern, T.S., and Kowluru, R.A. (2007). Oxidative damage in the retinal mitochondria of diabetic mice: possible protection by superoxide dismutase. Invest Ophthalmol Vis Sci 48, 3805-3811.

Kartha, G.K., Moshal, K.S., Sen, U., Joshua, I.G., Tyagi, N., Steed, M.M., and Tyagi, S.C. (2008). Renal mitochondrial damage and protein modification in type-2 diabetes. Acta Diabetol 45, 75-81.

Kelley, D.E., He, J., Menshikova, E.V., and Ritov, V.B. (2002). Dysfunction of mitochondria in human skeletal muscle in type 2 diabetes. Diabetes 51, 2944-2950.

Kim, J.A., Wei, Y., and Sowers, J.R. (2008). Role of mitochondrial dysfunction in insulin resistance. Circ Res 102, 401-414.

Kotronen, A., Seppala-Lindroos, A., Bergholm, R., and Yki-Jarvinen, $H$. (2008). Tissue specificity of insulin resistance in humans: fat in the liver rather than muscle is associated with features of the metabolic syndrome. Diabetologia 51, 130-138.

Lamson, D.W., and Plaza, S.M. (2002). Mitochondrial factors in the pathogenesis of diabetes: a hypothesis for treatment. Altern Med Rev 7, 94-111.

Leinninger, G.M., Backus, C., Sastry, A.M., Yi, Y.B., Wang, C.W., and Feldman, E.L. (2006a). Mitochondria in DRG neurons undergo hyperglycemic mediated injury through Bim, Bax and the fission protein Drp1. Neurobiol Dis 23, 11-22.

Leinninger, G.M., Edwards, J.L., Lipshaw, M.J., and Feldman, E.L. (2006b). Mechanisms of disease: mitochondria as new therapeutic targets in diabetic neuropathy. Nat Clin Pract Neurol 2, 620-628.

Lesnefsky, E.J., Slabe, T.J., Stoll, M.S., Minkler, P.E., and Hoppel, C.L. (2001). Myocardial ischemia selectively depletes cardiolipin in rabbit heart subsarcolemmal mitochondria. Am J Physiol Heart Circ Physiol 280, H2770-2778.

Lewis, E.J., and Lewis, J.B. (2003). Treatment of diabetic nephropathy with angiotensin II receptor antagonist. Clin Exp Nephrol 7, 1-8.

Li, J., Cai, T., Wu, P., Cui, Z., Chen, X., Hou, J., Xie, Z., Xue, P., Shi, L., Liu, P., et al. (2009). Proteomic analysis of mitochondria from Caenorhabditis elegans. Proteomics 9, 4539-4553.

Lieber, C.S., Leo, M.A., Mak, K.M., Xu, Y., Cao, Q., Ren, C., Ponomarenko, A., and DeCarli, L.M. (2004). Model of nonalcoholic steatohepatitis. Am J Clin Nutr 79, 502-509.

Lopez-Sanchez, L.M., Lopez-Pedrera, C., and Rodriguez-Ariza, A. (2012). Proteomics insights into deregulated protein S-nitrosylation and disease. Expert Rev Proteomics 9, 59-69.

Lowell, B.B., and Shulman, G.I. (2005). Mitochondrial dysfunction and type 2 diabetes. Science 307, 384-387.

Madsen-Bouterse, S.A., and Kowluru, R.A. (2008). Oxidative stress 
and diabetic retinopathy: pathophysiological mechanisms and treatment perspectives. Rev Endocr Metab Disord 9, 315-327.

Maechler, P., Carobbio, S., and Rubi, B. (2006). In beta-cells, mitochondria integrate and generate metabolic signals controlling insulin secretion. Int J Biochem Cell Biol 38, 696-709.

Maechler, P., Li, N., Casimir, M., Vetterli, L., Frigerio, F., and Brun, T. (2010). Role of mitochondria in beta-cell function and dysfunction. Adv Exp Med Biol 654, 193-216.

Maechler, P., and Wollheim, C.B. (2001). Mitochondrial function in normal and diabetic beta-cells. Nature 414, 807-812.

Mariappan, N., Elks, C.M., Sriramula, S., Guggilam, A., Liu, Z., Borkhsenious, O., and Francis, J. (2009). NF-kappaB-induced oxidative stress contributes to mitochondrial and cardiac dysfunction in type II diabetes. Cardiovasc Res 85, 473-483.

Mogensen, M., Sahlin, K., Fernstrom, M., Glintborg, D., Vind, B.F., Beck-Nielsen, H., and Hojlund, K. (2007). Mitochondrial respiration is decreased in skeletal muscle of patients with type 2 diabetes. Diabetes 56, 1592-1599.

Mollica, M.P., Lionetti, L., Crescenzo, R., D'Andrea, E., Ferraro, M., Liverini, G., and lossa, S. (2006). Heterogeneous bioenergetic behaviour of subsarcolemmal and intermyofibrillar mitochondria in fed and fasted rats. Cell Mol Life Sci 63, 358-366.

Mootha, V.K., Lindgren, C.M., Eriksson, K.F., Subramanian, A., Sihag, S., Lehar, J., Puigserver, P., Carlsson, E., Ridderstrale, M., Laurila E., et al. (2003). PGC-1alpha-responsive genes involved in oxidative phosphorylation are coordinately downregulated in human diabetes. Nat Genet 34, 267-273.

Moreira, P.I., and Oliveira, C.R. (2011). Mitochondria as potential targets in antidiabetic therapy. Handb Exp Pharmacol, 331-356.

Moreira, P.I., Santos, M.S., Sena, C., Nunes, E., Seica, R., and Oliveira, C.R. (2005a). CoQ10 therapy attenuates amyloid beta-peptide toxicity in brain mitochondria isolated from aged diabetic rats. Exp Neurol 196, 112-119.

Moreira, P.I., Santos, M.S., Sena, C., Seica, R., and Oliveira, C.R. (2005b). Insulin protects against amyloid beta-peptide toxicity in brain mitochondria of diabetic rats. Neurobiol Dis 18, 628-637.

Morino, K., Petersen, K.F., Dufour, S., Befroy, D., Frattini, J., Shatzkes, N., Neschen, S., White, M.F., Bilz, S., Sono, S., et al. (2005). Reduced mitochondrial density and increased IRS-1 serine phosphorylation in muscle of insulin-resistant offspring of type 2 diabetic parents. J Clin Invest 115, 3587-3593.

Munusamy, S., Saba, H., Mitchell, T., Megyesi, J.K., Brock, R.W., and Macmillan-Crow, L.A. (2009). Alteration of renal respiratory Complex-III during experimental type-1 diabetes. BMC Endocr Disord 9, 2.

Nishikawa, T., and Araki, E. (2007). Impact of mitochondrial ROS production in the pathogenesis of diabetes mellitus and its complications. Antioxid Redox Signal 9, 343-353.

Nishikawa, T., Edelstein, D., Du, X.L., Yamagishi, S., Matsumura, T., Kaneda, Y., Yorek, M.A., Beebe, D., Oates, P.J., Hammes, H.P., et al. (2000). Normalizing mitochondrial superoxide production blocks three pathways of hyperglycaemic damage. Nature 404, 787-790.

Ong, S.E., Blagoev, B., Kratchmarova, I., Kristensen, D.B., Steen, H., Pandey, A., and Mann, M. (2002). Stable isotope labeling by amino acids in cell culture, SILAC, as a simple and accurate approach to expression proteomics. Mol Cell Proteomics 1,
376-386

Pagliarini, D.J., Calvo, S.E., Chang, B., Sheth, S.A., Vafai, S.B., Ong, S.E., Walford, G.A., Sugiana, C., Boneh, A., Chen, W.K., et al. (2008). A mitochondrial protein compendium elucidates complex I disease biology. Cell 134, 112-123.

Pagliarini, D.J., and Dixon, J.E. (2006). Mitochondrial modulation: reversible phosphorylation takes center stage? Trends Biochem Sci 31, 26-34.

Pan, S., Chen, R., Aebersold, R., and Brentnall, T.A. (2010). Mass spectrometry based glycoproteomics-from a proteomics perspective. Mol Cell Proteomics 10, R110003251.

Patti, M.E., Butte, A.J., Crunkhorn, S., Cusi, K., Berria, R., Kashyap, S., Miyazaki, Y., Kohane, I., Costello, M., Saccone, R., et al. (2003). Coordinated reduction of genes of oxidative metabolism in humans with insulin resistance and diabetes: Potential role of PGC1 and NRF1. Proc Natl Acad Sci U S A 100, 8466-8471.

Patti, M.E., and Corvera, S. (2010). The role of mitochondria in the pathogenesis of type 2 diabetes. Endocr Rev 31, 364-395.

Patton, W.F. (2000). A thousand points of light: the application of fluorescence detection technologies to two-dimensional gel electrophoresis and proteomics. Electrophoresis 21, 1123-1144.

Petersen, K.F., Dufour, S., Befroy, D., Garcia, R., and Shulman, G.I. (2004). Impaired mitochondrial activity in the insulin-resistant offspring of patients with type 2 diabetes. N Engl J Med 350, 664-671.

Phillips, C.A., and Molitch, M.E. (2002). The relationship between glucose control and the development and progression of diabetic nephropathy. Curr Diab Rep 2, 523-529.

Rabilloud, T., Chevallet, M., Luche, S., and Lelong, C. (2010). Two-dimensional gel electrophoresis in proteomics: Past, present and future. J Proteomics 73, 2064-2077.

Rezaul, K., Wu, L., Mayya, V., Hwang, S.I., and Han, D. (2005). A systematic characterization of mitochondrial proteome from human T leukemia cells. Mol Cell Proteomics 4, 169-181.

Ritov, V.B., Menshikova, E.V., He, J., Ferrell, R.E., Goodpaster, B.H., and Kelley, D.E. (2005). Deficiency of subsarcolemmal mitochondria in obesity and type 2 diabetes. Diabetes 54, 8-14.

Rosen, E.D., and Spiegelman, B.M. (2006). Adipocytes as regulators of energy balance and glucose homeostasis. Nature 444, 847-853.

Ross, P.L., Huang, Y.N., Marchese, J.N., Williamson, B., Parker, K., Hattan, S., Khainovski, N., Pillai, S., Dey, S., Daniels, S., et al. (2004). Multiplexed protein quantitation in Saccharomyces cerevisiae using amine-reactive isobaric tagging reagents. Mol Cell Proteomics 3, 1154-1169.

Ruiz-Romero, C., and Blanco, F.J. (2009). Mitochondrial proteomics and its application in biomedical research. Mol Biosyst 5, 1130-1142.

Santos, J.M., Mohammad, G., Zhong, Q., and Kowluru, R.A. (2010). Diabetic retinopathy, superoxide damage and antioxidants. Curr Pharm Biotechnol 12, 352-361.

Santos, J.M., Tewari, S., Goldberg, A.F., and Kowluru, R.A. (2011). Mitochondrial biogenesis and the development of diabetic retinopathy. Free Radic Biol Med 51, 1849-1860.

Satapati, S., He, T., Inagaki, T., Potthoff, M., Merritt, M.E., Esser, V., Mangelsdorf, D.J., Kliewer, S.A., Browning, J.D., and Burgess, S.C. (2008). Partial resistance to peroxisome proliferator-activated 
receptor-alpha agonists in ZDF rats is associated with defective hepatic mitochondrial metabolism. Diabetes 57, 2012-2021.

Schmeichel, A.M., Schmelzer, J.D., and Low, P.A. (2003). Oxidative injury and apoptosis of dorsal root ganglion neurons in chronic experimental diabetic neuropathy. Diabetes 52, 165-171.

Shen, X., Zheng, S., Thongboonkerd, V., Xu, M., Pierce, W.M., Jr., Klein, J.B., and Epstein, P.N. (2004). Cardiac mitochondrial damage and biogenesis in a chronic model of type 1 diabetes. Am J Physiol Endocrinol Metab 287, E896-905.

Sivitz, W.I., and Yorek, M.A. (2009). Mitochondrial dysfunction in diabetes: from molecular mechanisms to functional significance and therapeutic opportunities. Antioxid Redox Signal 12, 537-577.

Sparre, T., Larsen, M.R., Heding, P.E., Karlsen, A.E., Jensen, O.N., and Pociot, F. (2005). Unraveling the pathogenesis of type 1 diabetes with proteomics: present and future directions. Mol Cell Proteomics 4, 441-457.

Suh, J.H., Heath, S.H., and Hagen, T.M. (2003). Two subpopulations of mitochondria in the aging rat heart display heterogenous levels of oxidative stress. Free Radic Biol Med 35, 1064-1072.

Suzuki, Y., Atsumi, Y., Matsuoka, K., Nishimaki, K., Ohta, S., Taniyama, M., and Muramatsu, T. (2005). Mitochondrial tRNA(Leu(UUR)) mutation at position 3243 detected in patients with type 1 diabetes. Diabetes Res Clin Pract 67, 92-94.

Taylor, S.W., Fahy, E., Zhang, B., Glenn, G.M., Warnock, D.E., Wiley, S., Murphy, A.N., Gaucher, S.P., Capaldi, R.A., Gibson, B.W., et al. (2003). Characterization of the human heart mitochondrial proteome. Nat Biotechnol 21, 281-286.

Tewari, S., Santos, J.M., and Kowluru, R.A. (2012). Damaged mitochondrial DNA replication system and the development of diabetic retinopathy. Antioxid Redox Signal 17, 492-504.

Thomson, M. (2002). Evidence of undiscovered cell regulatory mechanisms: phosphoproteins and protein kinases in mitochondria. Cell Mol Life Sci 59, 213-219.

Trudeau, K., Molina, A.J., Guo, W., and Roy, S. (2010). High glucose disrupts mitochondrial morphology in retinal endothelial cells: implications for diabetic retinopathy. Am J Pathol 177, 447-455.

Turko, I.V., Li, L., Aulak, K.S., Stuehr, D.J., Chang, J.Y., and Murad, F. (2003). Protein tyrosine nitration in the mitochondria from diabetic mouse heart. Implications to dysfunctional mitochondria in diabetes. J Biol Chem 278, 33972-33977.

Turko, I.V., and Murad, F. (2003). Quantitative protein profiling in heart mitochondria from diabetic rats. J Biol Chem 278, 35844-35849.

Turner, N., and Heilbronn, L.K. (2008). Is mitochondrial dysfunction a cause of insulin resistance? Trends Endocrinol Metab 19, 324-330.

Verkhratsky, A., and Fernyhough, P. (2008). Mitochondrial malfunction and $\mathrm{Ca} 2+$ dyshomeostasis drive neuronal pathology in diabetes. Cell Calcium 44, 112-122.

Vial, G., Dubouchaud, H., Couturier, K., Cottet-Rousselle, C., Taleux, N., Athias, A., Galinier, A., Casteilla, L., and Leverve, X.M. (2010). Effects of a high-fat diet on energy metabolism and ROS production in rat liver. J Hepatol 54, 348-356.

Wallace, D.C. (1999). Mitochondrial diseases in man and mouse. Science 283, 1482-1488.

Wang, Y., Peng, F., Tong, W., Sun, H., Xu, N., and Liu, S. (2010). The nitrated proteome in heart mitochondria of the $\mathrm{db} / \mathrm{db}$ mouse model: characterization of nitrated tyrosine residues in SCOT. J Proteome Res 9, 4254-4263.

Whiting, D.R., Guariguata, L., Weil, C., and Shaw, J. (2011). IDF diabetes atlas: global estimates of the prevalence of diabetes for 2011 and 2030. Diabetes Res Clin Pract 94, 311-321.

Wiederkehr, A., and Wollheim, C.B. (2006). Minireview: implication of mitochondria in insulin secretion and action. Endocrinology 147, 2643-2649.

Wilson-Fritch, L., Nicoloro, S., Chouinard, M., Lazar, M.A., Chui, P.C., Leszyk, J., Straubhaar, J., Czech, M.P., and Corvera, S. (2004). Mitochondrial remodeling in adipose tissue associated with obesity and treatment with rosiglitazone. J Clin Invest 114, 1281-1289.

Yu, T., Sheu, S.S., Robotham, J.L., and Yoon, Y. (2008). Mitochondrial fission mediates high glucose-induced cell death through elevated production of reactive oxygen species. Cardiovasc Res 79, 341-351.

Zhu, W., Smith, J.W., and Huang, C.M. (2010). Mass spectrometry-based label-free quantitative proteomics. J Biomed Biotechnol 2010, 840518.

Zimmet, P., Alberti, K.G., and Shaw, J. (2001). Global and societal implications of the diabetes epidemic. Nature 414, 782-787.

Zischka, H., Weber, G., Weber, P.J., Posch, A., Braun, R.J., Buhringer, D., Schneider, U., Nissum, M., Meitinger, T., Ueffing, M., et al. (2003). Improved proteome analysis of Saccharomyces cerevisiae mitochondria by free-flow electrophoresis. Proteomics 3, 906-916. 